American Journal of Pharmaceutical Education 2021; 85 (4) Article 8249.

\title{
RESEARCH
}

\section{Personal DNA Testing Increases Pharmacy Students' Confidence and Competence in Pharmacogenomics}

\author{
Mahfoud Assem, PhD, ${ }^{a}$ Ulrich Broeckel, MD, ${ }^{\mathrm{a}, \mathrm{b}}$ George E. MacKinnon, $\mathrm{PhD}^{\mathrm{a}}$ \\ ${ }^{a}$ Medical College of Wisconsin, School of Pharmacy, Milwaukee, Wisconsin \\ ${ }^{b}$ RPRD Diagnostics LLC, Milwaukee, Wisconsin
}

Submitted June 23, 2020; accepted December 22, 2020; published April 2021.

Objective. Pharmacogenomics, a key tool in personalized medicine, and therapeutic drug management is projected to become an integral part of pharmacy practice. This study describes an innovative pedagogy that used several interactive learning methods to increase learners' competence and perceptions in pharmacogenomics.

Methods. First-year student pharmacists at the Medical College of Wisconsin participated in lectures, discussions, and patient care laboratory training on the topic of pharmacogenomics. These students were given the opportunity to undergo personal pharmacogenomics testing. Before and after these activities, participants were surveyed about their attitudes towards the use of pharmacogenomics in current and future practice.

Results. Forty-five students participated in this voluntary personal pharmacogenomics testing and completed pre-course and post-course surveys. Significant improvements were seen in 22 of the 27 surveys questions responses from the pre-course to the post-course surveys. Student learning outcomes, competencies, and attitudes towards pharmacogenomics improved from a relatively neutral perception of pharmacogenomics to one of more confidence.

Conclusion. This study demonstrated that participation in a novel pedagogy that included voluntarily individual pharmacogenomics testing was beneficial to student pharmacists by improving knowledge, interest, and confidence in pharmacogenomics and its incorporation into their future pharmacy practice.

Keywords: active learning, learning outcome, perception, pharmacogenomics, survey

\section{INTRODUCTION}

Pharmacists are in a unique position to provide patient education and counseling in precision medicine and, specifically, pharmacogenomics. This position has been recognized by the Accreditation Council for Pharmacy Education (ACPE) in Standards 2016 Appendix 1, stating pharmacogenomics is the "genetic basis for disease and individual differences in metabolizing enzymes, transporters, and other biochemicals impacting drug disposition and action that underpin the practice of personalized medicine." ${ }^{1}$ Considering the need for pharmacy graduates to be competent in precision medicine and pharmacogenomics, it is important to incorporate material on these emerging areas into contemporary pharmacy curricula.

Pharmacy educators are striving to engage students within the classroom using a variety of teaching pedagogy

Corresponding Author: Mahfoud Assem, Medical College of Wisconsin, School of Pharmacy, 8701 W Watertown Plank Rd., Milwaukee, WI 53226. Tel: 414-955-2879. Email:

massem@mcw.edu to foster an interactive learning environment while ultimately gaining an appreciation for the impact that knowledge has on their understanding and application in a therapeutic area. ${ }^{2,3}$ The Medical College of Wisconsin's (MCW) new School of Pharmacy developed a required course, Principles of Drug Actions and Pharmacogenomics, in the three-year Doctor of Pharmacy (PharmD) curriculum. In addition, the topic of pharmacogenomics is included as a curricular thread throughout the PharmD program. To assess the effectiveness of the coverage of this material in the first year, we developed a study that used interactive and innovative approaches to teach pharmacogenomics to first year pharmacy students. Our study goals and objectives were to assess pharmacy students understanding and perceptions of pharmacogenomics.

\section{METHODS}

PharmD students (class of 2022) at the MCW School of Pharmacy were required to complete two courses, Principles of Drug Actions and Pharmacogenomics and 


\section{American Journal of Pharmaceutical Education 2021; 85 (4) Article 8249.}

Patient Care Laboratory during their first professional year. These two courses covered a broad range of lectures and practice techniques including basic pharmacology, medicinal chemistry, pharmacokinetics, principle of pharmacogenomics, applications to pharmacokinetics and pharmacodynamics. Additionally, the Clinical Pharmacogenetics Implementation Consortium (CPIC) guidelines, ethics, and patients counseling with respect to pharmacogenomics were covered.

We designed an intervention to allow students to be active participants in their own learning. The activity allowed students, for a temporary time, make the transition from student-learners to patient-learners. Students were asked to complete a pre-and post-intervention attitudinal survey of pharmacogenomics to determine attitudinal changes from baseline, as has been done by others in pharmacy education. ${ }^{4}$

Participants were asked to complete an anonymous pre-course survey on Qualtrics XM (Qualtrics) prior to starting the course. The survey was administered to assess students' baseline knowledge and attitude towards pharmacogenomics and how they believed they would use pharmacogenomics in their future role as a health care provider. Before completing the pre-course survey, students were provided a consent form that included a detailed description of the purpose, goals, and objectives of the study.

The survey consisted of 27 questions grouped in four categories: assessment of students' knowledge of pharmacogenomics testing, use of the information to counsel patients and other health care providers, application to future clinical pharmacy practices, and comfort with the practice of adapting medication regimens and patient counseling based on genetic information, and their future professional development. The survey items were from the University of Maryland School of Medicine (45\% of the questions $)^{5}$ and from an article by Coriolan and colleagues ( $18 \%$ of the questions), ${ }^{6}$ with the remaining created by the authors (37\% of the questions). Students' answers on the pre- and post-survey instruments were paired using anonymous self-selected codes. The scoring was performed according to the Likert 5-point scoring. Each choice was assigned a value from 1 to 5, as follows for the respective questions on understanding, confidence, and usefulness of pharmacogenomics: $(1=$ no understanding/extremely not confident/extremely not useful to $5=$ thorough understanding/extremely confident/extremely useful). The following scale was used for questions on perceptions of comfort and readiness $(1=$ strongly disagree, to $5=$ strongly agree). During analysis, the data was merged into two groups for percentage calculations: answers 1 and 2 versus answers 3, 4, and 5. The mean response and standard deviation were also calculated for each question and compared. Student learning outcomes and examinations scores were extracted from ExamSoft (Examsoft Worldwide, Inc).

All of the students were given the opportunity to voluntarily participate in a pharmacogenomics assay performed from a saliva specimen. Following consent, all samples were retained in a locked area and only handled by the investigators until the assays were run by RPRD Diagnostics (Milwaukee, WI). Genomic DNA from saliva was extracted and amplified by multiplex PCR. The PCR products from each student's amplified DNA were pooled, purified, fragmented, labeled, and hybridized to the PharmacoScan Array per the manufacturer's recommendations (ThermoFisher Scientific, Waltham, MA). Arrays were then stained with a fluorescent antibody and scanned on the GeneTitan Multi-Channel Instrument. The data were analyzed using the Axiom Analysis Suite 3.1 (ThermoFisher Scientific). Analysis was performed using the commercially released allele translation table (version R6). Pharmacogenomics data and other relevant demographic data were harvested and anonymously stored.

After the pharmacogenomics testing was conducted, each student who participated was given a copy of their personalized laboratory report. The report provided three sets of data: actionable results with phenotype and gene activity for genes with CPIC guidelines; phenotype and gene activity for genes with known pharmacogenetic functions but without CPIC guidelines; and genotypes for relevant genes that don't yet have any known clinical applications. Students were given two weeks to review their pharmacogenomics results. The genetic testing was $100 \%$ focused on genes relevant to pharmacogenomics (ie, mostly drug metabolism genes).

Students were asked to select a few markers of interest based on their and/or their relatives' medication history for a flipped classroom discussion. All students' data were appropriately clustered, assigned to a group based on the data and used to trigger active discussions. Within each cluster, at least one major genetic polymorphism was identified that was later selected as a subject of discussion in small groups of four to six students and in whole class activities using CPIC guidelines and PharmGKB data.

This study was approved by the MCW's institutional review board (IRB) and all participants provided informed consent. According to IRB protocols, genetic data collected from the "pharmacogenomics assay" was maintained by RPRD Diagnostics, and the primary investigators had no direct access to student-specific laboratory results as required by current laws on privacy and confidentiality. 


\section{American Journal of Pharmaceutical Education 2021; 85 (4) Article 8249.}

Statistical analyses were performed by $\mathrm{R}$ programming software, version 4, using the RStudio platform, version 1.2. All individual questions used a paired Wilcoxon signed-rank test to generate $p$ values and significance was set at a $p$ value under .05 .

\section{RESULTS}

A total of $45(100 \%)$ students were enrolled in both courses and $39(89 \%)$ agreed to personal pharmacogenomic testing. Students were provided with their pharmacogenomics report for analysis and use in class discussions. The students who declined to participate in the genetic testing received mock personal genetic test results to enable them to participate fully in class discussions and not identify them as not having received a personal pharmacogenomic result. The majority of students in the study cohort were 25 years of age, female $(60 \%)$, Caucasian $(60 \%)$, and had a bachelor's degree $(82 \%)$.

From the students' clustered pharmacogenomic data, the following genetic polymorphisms were identified and used to initiate student led discussions: CYP3A5 normal metabolizers (24\% heterozygotes and 4.4\% homozygotes), which are used in determining tacrolimus dosing; CYP2C9 poor metabolizers (9\%), which are used in determining warfarin dosing, CYP2C19 (24.4\%) rapid metabolizers, which are used in determining clopidogrel clinical response; and SLC01B1 decreased function $(30 \%)$, which is used in analyzing a patient's risk of developing rhabdomyolysis while taking statins.
All 45 pharmacy students enrolled in the course completed the pre- and post-course surveys. On the first survey item, which asked about students' understanding of the risks associated with pharmacogenomics, $55.3 \%$ of students indicated on the pre-intervention survey that they had little or no grasp of this concept before the course and activities. This percentage dropped to $6.7 \%$ after completion of the course (post-survey) (Table 1). Similarly, on the second survey item which evaluated students' knowledge about the potential benefits of pharmacogenomics, students indicated their understanding increased from $62 \%$ to $94 \%$. Furthermore, for the following set of questions relating to testing and test results interpretation in a clinical pharmacy setting, students' comprehension increased from an overall average of $32 \%$ before the course to $97 \%$ after the course (Table 1). The changes in all responses from the pre-course to the post-course survey were significant $(p<.001)$.

The next set of survey questions investigated students' confidence in conducting different aspects of pharmacogenomics consulting (Table 2). In terms of student's confidence in consulting patients, $77.8 \%$ of students indicated on the pre-survey that they had little or no confidence in their ability to consult patients in pharmacogenomics. After the completion of the courses, this percentage dropped to $4.4 \%$ on the post-survey. Concerning the confidence to discuss results with physicians and other prescribers, student confidence increased from $22.2 \%$ to $97.8 \%$. The last question assessed student confidence on the possibility of modifying a patient's

Table 1. Pharmacy Students' Understanding of Basic Pharmacogenomics and the Role of the Pharmacist in Personalized Medicine

\begin{tabular}{lcc}
\hline Survey question & Pre-Survey Mean (SD) & Post-Survey Mean (SD) \\
\hline $\begin{array}{l}\text { The risks of pharmacogenomic testing } \\
\text { The benefits of pharmacogenomic testing }\end{array}$ & $2.6(1.2)$ & $3.8(0.8)$ \\
$\begin{array}{l}\text { How to interpret pharmacogenomic testing } \\
\text { results }\end{array}$ & $2.9(1.2)$ & $4.1(0.7)$ \\
$\begin{array}{l}\text { How pharmacogenomic test results are used in } \\
\text { clinical practice }\end{array}$ & $2.4(0.8)$ & $3.7(0.7)$ \\
$\begin{array}{l}\text { The purpose of preemptive pharmacogenomic } \\
\text { testing }\end{array}$ & $2.4(1.1)$ & $3.9(0.7)$ \\
$\begin{array}{l}\text { The purpose of reactive pharmacogenomic } \\
\text { testing }\end{array}$ & $2.2(1.1)$ & $4.1(0.7)$ \\
$\begin{array}{l}\text { The role of pharmacists in collecting patient } \\
\text { samples/specimens for pharmacogenomic } \\
\text { testing }\end{array}$ & $2.2(1.1)$ & $3.0(0.7)$ \\
$\begin{array}{l}\text { The role of pharmacists in interpreting } \\
\text { pharmacogenomic testing results }\end{array}$ & $2.1(1.0)$ \\
\hline
\end{tabular}

Survey questions were evaluated using a five-point Likert scale: $1=$ no understanding, $2=$ little understanding, $3=$ average understanding, $4=$ above average understanding, and $5=$ thorough understanding

All individual questions used a paired Wilcoxon signed-rank test to generate $p$ values

All results are significant at a $p<.001$ 


\section{American Journal of Pharmaceutical Education 2021; 85 (4) Article 8249.}

Table 2. Pharmacy Students' Confidence in Conducting Different Aspects of Pharmacogenomics Consulting

\begin{tabular}{lcc}
\hline Survey question & $\begin{array}{c}\text { Pre-Survey } \\
\text { Mean (SD) }\end{array}$ & $\begin{array}{c}\text { Post-Survey } \\
\text { Mean (SD) }\end{array}$ \\
\hline $\begin{array}{l}\text { How confident would you feel explaining } \\
\text { pharmacogenomic test results to a patient? }\end{array}$ & $1.8(0.9)$ \\
$\begin{array}{l}\text { How confident would you feel discussing } \\
\text { pharmacogenomic test results with } \\
\text { physicians and other prescribers? }\end{array}$ & $1.7(1.0)$ \\
$\begin{array}{l}\text { How confident would you feel modifying a } \\
\text { patient's medications (that may include } \\
\text { changing a medication) based on } \\
\text { pharmacogenomic test results? }\end{array}$ & $1.9(0.9)$ \\
\hline
\end{tabular}

Survey questions were evaluated using a 5-point Likert scale: $1=$ extremely not confident, $2=$ not confident, $3=$ neutral, $4=$ confident, and

$5=$ extremely confident

All individual questions used a paired Wilcoxon signed-rank test to generate $p$ values

All results are significant at the $p<.001$

$\mathrm{SD}=$ Standard deviation

medications based on pharmacogenomics test results. The perception jumped from $20 \%$ to $89 \%$. Here, too, the changes in all responses from pre-to-post survey administration were significant $(p<.001)$. The next group of three questions assessed the usefulness of pharmacogenomics testing (Table 3 ). While there were changes in perceptions from baseline of usefulness, they were not significant.

The final set of questions investigated students' comfort about their future readiness in pharmacogenomics prescribing, results analysis, and patients counseling (Table 4). This set was the largest in the survey and included 13 questions exploring all aspects of pharmacy practice and future specialization in the area of pharmacogenomics. Student responses improved from approximately $30 \%$ to over $90 \%(p<.001)$ on all but two of the 13 questions. The overall evaluation scores for the two questions in the pre-survey were high and the scores improved only slightly on the post-survey. These two items were question 13, "Pharmacogenomics is a useful tool that pharmacists and medical professionals can use to optimize medication efficacy and/or prevent adverse events," and question 12, "Post-graduation, I intend to read up on pharmacogenomics especially on how it influences my practice and/or specialty."

To assess objective data, in addition to the subjective results of the survey, we compared student learning outcome data from quizzes and examinations using ExamSoft for this cohort of students (class of 2022) with that of the previous two cohorts (i.e., class of 2020 and 2021) who did not participate in this new activity but did complete the identical two-course sequence, covered the same

Table 3. Pharmacy Students' Perception of the Usefulness of Pharmacogenomics Testing

\begin{tabular}{|c|c|c|}
\hline Survey question & $\begin{array}{l}\text { Pre-Survey } \\
\text { Mean (SD) }\end{array}$ & $\begin{array}{c}\text { Post-Survey } \\
\text { Mean (SD) }\end{array}$ \\
\hline $\begin{array}{l}\text { In general, how useful do you feel } \\
\text { pharmacogenomic testing will be in the } \\
\text { clinical setting? }\end{array}$ & $4.0(1.3)$ & $4.5(0.7)$ \\
\hline $\begin{array}{l}\text { In general, how useful do you feel } \\
\text { pharmacogenomic testing will be in the } \\
\text { pharmacy setting? }\end{array}$ & $3.8(1.4)$ & $4.4(0.7)$ \\
\hline $\begin{array}{l}\text { In general, how useful do you feel } \\
\text { pharmacogenomic test results are to the } \\
\text { pharmacist's care of patients? }\end{array}$ & $3.8(1.5)$ & $4.5(0.7)$ \\
\hline
\end{tabular}

Survey questions were evaluated using a 5-point Likert scale: $1=$ extremely not useful, $2=$ not useful, $3=$ neutral, $4=$ useful, and $5=$ extremely useful

All individual questions used a paired Wilcoxon signed-rank test to generate $p$ values

All results were not significant

$\mathrm{SD}=$ standard deviation 


\section{American Journal of Pharmaceutical Education 2021; 85 (4) Article 8249.}

Table 4. Pharmacy Students' Comfort Level Regarding Their Future Readiness in Pharmacogenomics Prescription, Analysis, and Counseling

\begin{tabular}{|c|c|c|}
\hline Survey question & Pre-Survey Mean (SD) & Post-Survey Mean (SD) \\
\hline $\begin{array}{l}\text { I would feel comfortable ordering } \\
\text { pharmacogenomic testing }\end{array}$ & $2.8(1.2)$ & $3.7(0.6)^{\mathrm{a}}$ \\
\hline $\begin{array}{l}\text { I would feel comfortable explaining the process } \\
\text { of pharmacogenomic testing to patients }\end{array}$ & $2.4(1.0)$ & $4.0(0.6)^{\mathbf{a}}$ \\
\hline $\begin{array}{l}\text { I would feel comfortable discussing } \\
\text { pharmacogenomic test results with patients }\end{array}$ & $2.2(1.0)$ & $4.0(0.6)^{\mathrm{a}}$ \\
\hline $\begin{array}{l}\text { I believe that pharmacogenomic testing is } \\
\text { critical for determining appropriate } \\
\text { healthcare }\end{array}$ & $3.3(1.1)$ & $4.0(0.7)^{\mathbf{a}}$ \\
\hline $\begin{array}{l}\text { I would feel comfortable discussing genetics in } \\
\text { general with patients }\end{array}$ & $2.9(1.0)$ & $3.9(0.7)^{\mathbf{a}}$ \\
\hline $\begin{array}{l}\text { I believe that pharmacogenomic testing is } \\
\text { critical for determining appropriate } \\
\text { medication selection and regimens (dose and } \\
\text { frequency) in patients }\end{array}$ & $3.4(1.1)$ & $3.9(0.6)^{\mathbf{b}}$ \\
\hline $\begin{array}{l}\text { I would feel comfortable discussing } \\
\text { pharmacogenomic test results with } \\
\text { physicians and other prescribers }\end{array}$ & $2.3(1.0)$ & $3.8(0.6)^{\mathbf{a}}$ \\
\hline $\begin{array}{l}\text { I would feel comfortable modifying a patient's } \\
\text { medications (that may include changing a } \\
\text { medication) based on pharmacogenomic test } \\
\text { results }\end{array}$ & $2.3(1.1)$ & $3.8(0.7)^{\mathbf{a}}$ \\
\hline $\begin{array}{l}\text { Pharmacogenomics is an integral part of the } \\
\text { pharmacy profession }\end{array}$ & $3.4(1.0)$ & $4.0(0.7)^{\mathbf{a}}$ \\
\hline $\begin{array}{l}\text { Pharmacogenomics may be an integral part of } \\
\text { my practice as a pharmacist }\end{array}$ & $3.5(1.0)$ & $4.0(0.7)^{\mathbf{a}}$ \\
\hline $\begin{array}{l}\text { I may encounter pharmacogenomics-related } \\
\text { questions during my practice as a pharmacist }\end{array}$ & $3.6(0.0)$ & $4.0(0.6)^{\mathbf{b}}$ \\
\hline $\begin{array}{l}\text { Post-graduation, I intend to read up on } \\
\text { pharmacogenomics especially on how it } \\
\text { influences my practice and/or specialty }\end{array}$ & $3.6(1.0)$ & $3.9(0.6)$ \\
\hline $\begin{array}{l}\text { Pharmacogenomics is a useful tool that } \\
\text { pharmacists and medical professionals can } \\
\text { use to optimize medication efficacy and/or } \\
\text { prevent adverse events }\end{array}$ & $3.8(0.9)$ & $4.1(0.6)$ \\
\hline
\end{tabular}

Survey questions were evaluated using a 5 -point Likert scale: $1=$ strongly disagree, $2=$ disagree, $3=$ neither disagree or agree, $4=$ agree, and $5=$ strongly agree

All individual questions used a paired Wilcoxon signed-rank test to generate $p$ values

${ }^{\text {a }} p<.001$

${ }^{\mathrm{b}} p<.05$

material, and had the same instructors of record. Although not significant, a trend toward improvement in overall course grades was seen when the aggregate classes were compared: 2020 class $(n=43) 79 \% \pm 7.6 \%, 2021$ class $(\mathrm{n}=51) 79 \% \pm 7.61 \%$, and 2022 class $(\mathrm{n}=45) 82 \% \pm$ $7.71 \%$ (Mean $\pm \mathrm{SD}$ ).

The six students who declined to undergo pharmacogenomics testing still received a mock report for analysis that contained some of the same conditions in other students. We also assessed the aggregate performance of these students compared with the rest of the class and saw a significant improvement but to a lesser extent than seen among students who participated in the testing (53\% improvement vs. $60.8 \%$ in the participating group; $p=.036$ ).

\section{DISCUSSION}

Pharmacogenomics has been a subject of interest for pharmaceutical and medical educators for over a decade. Several health science universities started implementing 


\section{American Journal of Pharmaceutical Education 2021; 85 (4) Article 8249.}

clinical pharmacogenomics courses in their curriculum with some minor success. ${ }^{7}$ Indeed, many studies have shown that medical and pharmacy students are not certain about including pharmacogenomics in their future practices despite having some knowledge in this area. ${ }^{4,5,7}$

We used an innovative approach to teaching pharmacogenomics. Our approach combined the benefits of a flipped classroom, standard lecture, patient care laboratory, and personal genetic data to increase student competencies in pharmacogenomics. The flipped classroom focuses on critical thinking, independent active learning, and engaged discussions among students with teachers. For example, during the student-led discussions, one member of the class volunteered a personal family history related to heart disease and nonresponse to clopidogrel following surgery. Genetic analysis showed that the student was a CYP2C19 poor metabolizer, which could explain the inefficacy of clopidogrel. Another student discussed their complicated response to antidepressants that may have been related to their CYP2D6 metabolism status. Such real-life examples from students are very helpful in demonstrating relevance to this topic.

This kind of comprehensive approach has previously been shown to increase student learning outcomes and competencies. ${ }^{8}$ Similar studies have been performed in elective courses and in postgraduate programs (eg, MS degree, postgraduate residency) with only a portion of the class. ${ }^{3,9,10}$ In contrast, our study included an entire class of PharmD students who were participating in required courses. By selecting the whole class for the study, we minimized the potential biases and overestimations that can result from using only highly motivated students who sign up for an elective course and may already have strong feelings about the subject.

Expanding pharmacogenomics education, using various delivery approaches, has been explored to improve patient care using therapeutic regimen optimization based on genetic makeup. Furthermore, several published studies have not assessed competency, ${ }^{9,11}$ whereas our current study tried to implement several learning processes including personal genetic testing to simulate reallife scenarios of patient care.

Our data supports that the combination of several activities improves students' confidence and comfort with implementing pharmacogenomics in their training and future practice. This improvement clearly increased with the addition of students' personalized analyses of their own pharmacogenomic results as reflected by the positive shift in responses from the pre-survey to the post-survey. Providing students the opportunity to voluntarily share personal anecdotes related to gene-drug pairings with their classmates was valuable in helping them to understand the relevance and clinical utility of pharmacogenomics. With respect to assessment, participant examination performance improved compared to that of the previous years of cohorts of students that did not have this activity but had all other content delivered in the same way.

Analyzing and discussing their own pharmacogenomic results in relation to different gene-drug pairs and by counselling each other, students' interest and level of confidence in incorporating this material into their future practice increased. Similar results have been observed in other studies, ${ }^{11,12}$ although they used other approaches to teaching pharmacogenomics. In agreement with several studies, ${ }^{2,3,10}$ competencies and learning outcomes related to pharmacogenomics have seen the greatest improvement for the majority of surveyed questions in our study.

Responses to the last set of questions in the presurvey, before students had taken the course, clearly demonstrated that they were aware of the importance of pharmacogenomics to the future of pharmacy practice. This awareness of the importance of pharmacogenomics increased after participating in the study as shown by student responses on the post-survey. Indeed, our results indicated that pharmacy students at the MCW School of Pharmacy are strongly considering using pharmacogenomics testing to alter and optimize patients' therapies. Given that the demographics of our pharmacy students are comparable to those of other pharmacy students, one might anticipate similar results if this approach was replicated.

In agreement with recent publications, ${ }^{4,9}$ our study provides a foundation that introducing pharmacogenomics as described, may have a positive impact on students' readiness to use pharmacogenomics in their future clinical practice. Based on these study findings, we are planning to expand our pedagogical approach to pharmacogenomics instruction to all future pharmacy students. We plan to keep surveying student pharmacists to assess the evolution of their attitudes toward and perceptions about pharmacogenomics counseling throughout the PharmD curriculum.

The six students who declined to participate in the pharmacogenomic testing were provided a mock report that enabled them to participate in class similarly to the other students. Their survey data were relatively similar to that received by the rest of the class in their reports, suggesting that participation albeit not from a personal pharmacogenomic assay, did have an impact on students' perceptions about incorporating pharmacogenomics in their learning. 


\section{American Journal of Pharmaceutical Education 2021; 85 (4) Article 8249.}

There are some limitations of our work. Given the nature of the pre- and post-surveys administered to students, there is the possibility that response-shift bias occurred that may have resulted in inaccurate pretest ratings. One approach to reducing response shift bias is to ask subjects to reassess their judgment of their pre-program level of functioning following the post-survey. Unfortunately, a "retrospective-pretest" following the post-survey was not performed in this study.

\section{CONCLUSION}

Our study supports the use of a combination of didactic lectures, practice laboratory counseling activities, and student-led group discussions, coupled with studentspecific personal pharmacogenomics testing, to improve pharmacy students' learning, interest, confidence, and perceptions in learning pharmacogenomics. An innovative teaching structure that includes undergoing a pharmacogenomics assay and reviewing and sharing their results with classmates will help prepare future pharmacists with the skills, competencies, and confidence to incorporate pharmacogenomics into future pharmacy practice.

\section{ACKNOWLEDGMENTS}

We are very grateful to all our student pharmacists who willingly and enthusiastically participated in this study; Mathew Letizia, PharmD, first year director of Professional Laboratories, for collaborative engagement; Erin Walcheske, Joel P. Spiess, and Sarah Fittanto for management and distribution of the survey and consent forms; and Aaron N. Winn, PhD, for statistical support.

Funding for this study was received from RPRD Diagnostics, LLC, Milwaukee, WI, and from the Medical College of Wisconsin School of Pharmacy.

\section{REFERENCES}

1. Accreditation Council for Pharmacy Education. Accreditation Standards and Key Elements for the Professional Program in Pharmacy Leading to the Doctor of Pharmacy Degree ("Standards 2016"). Published February 2015. Standards2016FINAL.pdf (acpeaccredit.org). Accessed April 1, 2021.

2. Kisor DF, Farrell CL. Expanding pharmacist and student pharmacist access genetics/genomics/pharmacogenomics competency education. J Med Educ Curric Dev. 2019;6: 2382120519834325.

3. Weitzel KW, Aquilante CL, Johnson S, Kisor DF, Empey PE. Educational strategies to enable expansion of pharmacogenomicsbased care. Am J Health Syst Pharm. 2016;73(23):1986-1998. 4. Marcinak R, Paris M, Kinney SRM. Pharmacogenomics education improves pharmacy student perceptions of their abilities and roles in its use. Am J Pharm Educ. 2018;82(9):6424.

5. Perry CG, Malone y KA, Beitelshees AL, et al. Educational innovations in clinical pharmacogenomics. Clin Pharmacol Ther. 2016;99(6):582-584. 6. Coriolan S, Arikawe N, Moscati A, Zhou L. Dym S. Pharmacy students' attitudes and perceptions toward pharmacogenomics education. Am J Health Syst Pharm. 2019;76(11):836-845.

7. Overby CL, Erwin AL, Abul-Husn NS, et al. Physician attitudes toward adopting genome-guided prescribing through clinical decision support. J Pers Med. 2014;4:35-44.

8. Munson A, Pierce R. Flipping content to improve student examination performance in a pharmacogenomics course. $\mathrm{Am} \mathrm{J}$ Pharm Educ. 2015;79(7):103.

9. Haidar CE, Hoffman JM, Gammal RS, Relling MV, Crews KR. Development of a post-graduate year 2 pharmacy residency in clinical pharmacogenetics. Am J Health Syst Pharm. 2017;74(6): 409-415.

10. Weitzel KW, McDonough CW, Elsey AR, Burkley B, Cavallari LH, Johnson JA. Effects of using personal genotype data on student learning and attitudes in a pharmacogenomics course. Am J Pharm Educ. 2016;80(7):122.

11. Powers KE, Buffington TM, Contaifer D Jr, Wijesinghe DS, Donohoe KL. Implementation of an active-learning laboratory on pharmacogenetics. Am J Pharm Educ. 2019;83(3):6605.

12. Gàlvez-Peralta M, Szklarz GD, Geldenhuys WJ, Lockman PR. An effective approach to teaching pharmacogenomics in the first year of pharmacy curriculum. Am J Pharm Educ. 2018;82(8):6345. 